\title{
La motivación, factor clave para el éxito en la educación a distancia en la UNED
}

\author{
Ana Victoria Wo Ching*
}

\begin{abstract}
RESUMEN
La educación a distancia, ofrecida en Costa Rica por la UNED, permite a miles de estudiantes de distintas procedencias geográficas y socioeconómicas el acceso a la educación superior. A pesar de las ventajas que proporciona, un alarmante porcentaje de estudiantes abandonan sus estudios cuando recién empiezan. La deserción estudiantil podría ser disminuida si se logra aumentar la motivación, tanto del estudiantado como del cuerpo docente. La evaluación formativa, el mejoramiento de la calidad del material didáctico y la utilización de estrategias lúdicas de aprendizaje deben aplicarse para motivar al alumnado y cultivar en él la necesidad de aprender.
\end{abstract}

Palabras clave: Motivación, educación a distancia, desmotivación, deserción estudiantil, autodeterminación, necesidad de aprender, comunicación no presencial, evaluación formativa.

\section{ABSTRACT}

Distance education, provided by UNED in Costa Rica, allows thousands of students of different geographic and socioeconomic origins the access to higher education. Even though it offers many advantages, an alarming rate of students drop out soon after they begin. Desertion could be lowered if motivation rises. Formative evaluation, improvement of the quality of the teaching learning materials and ludic teaching strategies must be applied in order to motivate students and cultivate the need to learn.

Keywords: Motivation, distance education, self-determination, need to learn, non-presencial communication, formative evaluation.

Bióloga graduada en la UCR. Licenciada en Manejo de Recursos Naturales, UNED. Tutora de la Cátedra de Ecología y Educación Ambiental en la Escuela de Ciencias, UNED. 
Es innegable la cantidad de ventajas que proporciona la educación a distancia, pues derriba las barreras de la distancia y permite que muchos estudiantes de distintos orígenes $\mathrm{y}$ variadas condiciones puedan incrementar su acervo de conocimientos. La Universidad Estatal a Distancia, UNED, es la única institución de educación superior en Costa Rica que ofrece la posibilidad del estudio a distancia. Desde 1977, esta oportunidad ha sido aprovechada por muchos costarricenses que ven en esta universidad una solución para mejorar su calidad de vida.

No obstante, aunque la educación a distancia sea vista como una panacea, puede convertirse en una frustración. Un gran porcentaje de quienes inician la aventura de estudiar a distancia no finalizan su educación. Al respecto, Castillo (2008) reporta un dato alarmante: al cabo de un año de iniciados sus estudios, "el $50 \%$ de los estudiantes han abandonado la UNED"' (p. 28).

Las obligaciones familiares $y$ laborales, así como las limitaciones económicas, indudablemente son factores que inciden en gran parte de las deserciones estudiantiles en la UNED; sin embargo, ¿acaso no hemos presenciado el caso de estudiantes que sortean múltiples dificultades en distintos ámbitos de su vida y logran finalizar su carrera con éxito? ¿Cómo logran mantener vivo el fuego interno que los induce a perseverar hasta alcanzar la meta? Por otra parte, en la deserción estudiantil no solo influyen problemas relacionados con los alumnos, sino también con el sistema y los tutores, los cuales a veces terminan por desmotivar al estudiantado.

La motivación es, en mi opinión, la clave que hace la diferencia en la educación a distancia. En la UNED es imprescindible trabajar continuamente en la motivación del estudiantado y del cuerpo docente.

\section{¿Por qué surge desmotivación en vez de motivación?}

La persona que se matricula por primera vez en un sistema de educación a distancia puede sentirse extraviada, necesitada de una mano que le oriente y le haga sentirse apoyada en sus estudios. García A. (2005) menciona que un reto de la enseñanza a distancia recae en la necesidad de relacionarse con otras personas, de manera que "prescindiendo de la habitual presencia cara a cara de profesor y alumnos, se pueda mantener un eficaz sistema de comunicación no presencial" (p. 9). Aunque la UNED tenga centros universitarios en muchos lugares del país, es común escuchar quejas de nuestros estudiantes acerca de la confusión que han experimentado no solo al realizar trámites administrativos sino también al estudiar diversas materias sin la guía presencial de un docente. La indiferencia que perciba un estudiante por 
parte de un docente o administrativo también influirá, aunque sean contadas las ocasiones en que estudiante y tutor o administrativo se encuentren frente a frente en una institución de educación a distancia. Por más que hayan leído o averiguado sobre la educación a distancia, no todos los que ingresan a la UNED vendrán preparados para enfrentar este sistema educativo $\mathrm{y}$ sus particularidades.

Por otra parte, una cantidad considerable de estudiantes me han afirmado que ciertas materias no les interesan en absoluto. Su fin único y último parece ser aprobar para poder obtener un título. Parte de su desmotivación hacia los cursos podría provenir del sistema de evaluación de la UNED, el cual es virtualmente idéntico al de las instituciones de educación presencial. En muchos cursos simplemente no existe la posibilidad de pensar creativamente, pues la evaluación exige memorizar una gran cantidad de datos muy específicos, sin permitir aplicarlos de manera constructiva y de utilidad para la vida real.

Los tutores también influyen en esta situación. Muchos docentes caen en el error de apresurarse con el programa del curso sin hacer un 'alto en el camino' (o varios “altos") a fin de examinar si lo que están haciendo está en función del alumnado y éste está aprovechando las tutorías. En muchas ocasiones, la tutoría se convierte en una tradicional clase magistral y, lo que es peor, una clase muy aburrida que podría hacer al estudiante preguntarse si la carrera que escogió es verdaderamente digna de su vocación.

Cabe mencionar aquí el tema de la corrupción como factor desmotivante. En mi época de estudiante de la Licenciatura en Protección y Manejo de los Recursos Naturales, dos compañeros de un curso me comunicaron que mi trabajo final fue plagiado por nuestra tutora, quien lo hizo pasar como suyo. Mi desilusión inicial fue seguida por una gran desmotivación, tanto en torno a la corrupción mostrada por dicha tutora como hacia la UNED; en ese momento pensé que la institución no seleccionaba bien a sus tutores y que éstos no tenían ni la capacidad intelectual para producir sus propias investigaciones de calidad, ni la moral requerida para educar a otros. Esa desmotivación me hizo cuestionarme si valía la pena seguir en este lugar, si me encontraría con otro tutor igual. Mis compañeros me dijeron que ellos experimentaron la misma situación con otros tutores y también la misma sensación de desmotivación; no obstante, me aconsejaron valorar los múltiples beneficios que ofrecía la UNED.

Los y las estudiantes en ocasiones también mencionan algunos inconvenientes que presentan los libros que acompañan las materias: no son atractivos, son aburridos, son relativamente difíciles de comprender ( $\sin$ la guía de un tutor) y la información que 
contienen no se relaciona con situaciones de la vida real ni es adecuada al entorno del estudiantado.

La desmotivación del alumnado es un gran problema, pues puede impulsar la deserción estudiantil. Esta situación, a su vez, podría desmotivar a los docentes y aumentar la apatía general en la institución.

\section{¿Qué podemos hacer para lograr la motivación en el entorno estudiantil?}

Moreno (1977) indica que un estudiante motivado, con base en sus propios intereses y sus propias necesidades, estará en las mejores circunstancias para aprender. Por eso, "será vital cultivar en el alumno la necesidad de aprender; entonces podremos considerarlo realmente motivado" ( $\mathrm{p}$. 40). Esta autora tiene la clave tanto de la educación presencial como de la educación a distancia: que el estudiante se sienta dueño de su educación porque la necesita, la quiere y es en parte responsable de ella.

Karsenti (1999) reafirma en gran medida la idea de Moreno; para él, el sentimiento de autodeterminación es el principio determinante de la motivación. Un estudiante autodeterminado sentirá mayor responsabilidad sobre las decisiones que toma en relación con su aprendizaje, por lo que estará más motivado en hacerse cargo de sus estudios.

Si bien es cierto que el desempeño académico depende en gran parte de la determinación individual del estudiante, también es posible afirmar, sin temor a equivocarnos, que los tutores son capaces de influir enormemente en la motivación y en el éxito del alumnado.

Primero debemos preguntarnos cómo es posible lograr un mayor número de estudiantes y docentes motivados en la UNED sin el contacto persona a persona, y cómo mantener una comunicación no presencial eficaz, para que la educación sea de elevada calidad. Si logramos que la educación a distancia sea verdaderamente una enseñanza sin distancias, entonces habremos avanzado un gran paso. Cierto es que no vivimos aislados en este mundo y que debemos recibir una continua retroalimentación por parte de nuestros estudiantes y de otros docentes. La UNED en este sentido está avanzando grandes distancias al desarrollar continuamente su plataforma tecnológica y propiciar la comunicación entre alumnos y alumnos, alumnos con docentes y docentes con docentes mediante foros, cursos y otros métodos que disminuyen efectivamente la brecha de la comunicación no presencial.

Los y las docentes podemos ayudar a nuestros estudiantes a familiarizarse con los recursos tecnológicos de la UNED, explicándoles paso a paso su función y uso. Si la opción de establecer foros virtuales no es posible, el docente podría abrir otros canales de comunicación con sus estudiantes, tales como el correo electrónico, método 
que personalmente aplico con excelentes resultados. De esta manera, es posible responder las dudas académicas, hacer recordatorios de fechas importantes y compartir información interesante relacionada sobre la materia. Esto le hace sentir a los estudiantes que no están solos; especialmente si ingresan por primera vez a la UNED, o si no han logrado acoplarse aún al sistema de enseñanza a distancia.

En las tutorías presenciales podemos emplear técnicas lúdicas como juegos para aplicar los conocimientos adquiridos o reforzarlos. Tales recursos disminuyen la probabilidad de aburrimiento. Además, deberíamos enseñarle a nuestros estudiantes técnicas efectivas de estudio como la elaboración de mapas conceptuales o cuadros comparativos, entre otros.

Material didáctico útil. Aunque los docentes no siempre son los responsables de crear el material didáctico de los cursos, tampoco deben permanecer ajenos a este aspecto de la educación a distancia. Dentro de los lineamientos establecidos por la UNED (2007) se plantea la necesidad de incorporar en los materiales didácticos "la multimedialidad, la hipertextualidad, las metáforas pedagógicas, la animación y otros recursos de la imagen y del texto, con alto valor comunicacional educativo y con un valor estético agregado, para lograr la mayor identificación de los estudiantes con sus materias y sus contenidos" (p. 14).
Si todos los materiales didácticos de la UNED cumplieran con esos lineamientos, muy probablemente aumentaría la motivación del estudiantado para estudiar por su cuenta y se lograría un aprendizaje más significativo. El material didáctico es un componente muy relevante en la educación a distancia, ya que media el contenido a ser adquirido por el estudiantado y facilita el aprendizaje.

El cuerpo docente puede contribuir a que lo anterior se logre, al conversar con los encargados de cátedra sobre las necesidades de los estudiantes y sugerirles las características que debe tener el material didáctico; por ejemplo, tiene que mostrar contenidos actuales y veraces; estimular a los estudiantes a estudiar, hacer que se interesen genuinamente por la información, recordarles lo que han estudiado en cursos previos y promover la aplicación de los contenidos a situaciones de la vida real. El material didáctico, en cualquiera de sus formas, debe proponer actividades que fomenten el pensamiento crítico y creativo, ayudando a los estudiantes a aplicar los conocimientos adquiridos a situaciones reales de su interés. Además, debe permitir que el estudiante se autoevalúe a través de ejercicios que le ayuden a afianzar el conocimiento y comprobar su progreso.

Evaluar para formar. Parte de la visión con que fue creada la UNED ha sido la formación de personas con capacidad para razonar críticamente y 
adaptarse creativamente a los cambios de su entorno. Sin embargo, en muchos cursos de esta universidad los estudiantes no siempre pueden hacer uso de su capacidad crítica, buscar soluciones para resolver estudios de caso, efectuar investigaciones sobre algún tema de su interés ni compartir sus experiencias con los demás estudiantes.

Entonces, ¿cómo propiciar el cumplimiento de los objetivos del plan de estudio, motivar a nuestros estudiantes a pensar creativa y críticamente, y a la vez evaluar el aprendizaje?

La evaluación formativa nos puede ayudar a lograr estas metas, ya que con ella los tutores de la UNED podemos analizar el progreso del estudiante y localizar sus deficiencias durante el estudio de un tema, para ayudarle a corregirlas.

Moreno (1977) señala que si la evaluación formativa indica que "se van cumpliendo los objetivos, el maestro y los alumnos tendrán un estímulo eficaz pare seguir adelante. $\mathrm{Si}$ la evaluación formativa muestra deficiencias o carencias en cuanto a los objetivos que pretenden alcanzarse, será tiempo de hacer las rectificaciones y ajustes necesarios al plan, de motivar nuevamente a los alumnos y de examinar si los objetivos señalados son los más oportunos para colocarse en esa precisa etapa del proceso enseñanza-aprendizaje" (p.53).
Hay diversas estrategias que se pueden emplear para la evaluación formativa en las tutorías de la UNED. En mi caso, para asignaturas percibidas por los alumnos como difíciles -por ejemplo Anatomía y Fisiología Vegetal-, he fomentado trabajos grupales (en forma de concursos, trivias y otras estrategias lúdicas) en los que les doy a los estudiantes la oportunidad de coevaluarse. Esta forma de trabajo y evaluación brinda a los estudiantes habilidades para el trabajo en equipo y les permite ser evaluados, de una forma más relajada, por sus iguales. Al tutor le posibilita detectar en qué aspectos es necesario profundizar y cuáles estudiantes requieren de mayor atención.

Es necesario que revisemos nuestro quehacer docente continuamente y lo adecuemos siempre a las necesidades de nuestro estudiantado. Como lo establece el marco estratégico de la UNED, los docentes somos parte de una sola institución y nuestros aportes en acciones, ideas y pensamientos contribuirán a llevar a cabo la misión de la UNED.

Desde el punto de vista del estudiante, la educación a distancia puede ser una experiencia sumamente enriquecedora, si tiene la motivación para perseverar y seguir aprendiendo por su cuenta. La labor de los docentes es vital para motivar esa necesidad de aprendizaje. 


\section{Bibliografía}

Castillo, M. (2008). Tasas de Deserción en la Universidad Estatal a Distancia de Costa Rica. Actualidades Investigativas en Educación, 8(1), 1-32.

García Aretio, L. (1999). Fundamento y componentes de la educación a distancia. España. Recuperado en marzo de 2010, de http://ipes.anep.edu.uy/documentos/ libre_asis/materiales/fundamento_componentes_EAD.pdf
Karsenti, T. (1999). Student Motivation and Distance Education on the Web: Love at First Sight? Recuperado en mayo de 2010, de http://www.unb.ca/naweb/proceedings/1999/karsenti/karsenti.html

Moreno, M. (1977). Didáctica. Fundamentación y práctica. México: Editorial Progreso.

UNED. (2007, noviembre). Lineamientos de Política Institucional 2007-2011. Aprobados por la Asamblea Universitaria en sesión 074-2007, San José, Costa Rica. 
